\title{
Plant Regeneration from in Vitro Culture of Embryonic Axis Explants in Common and Tepary Beans
}

\author{
Mohamed F. Mohamed ${ }^{1}$, Paul E. Read ${ }^{2}$, and Dermot P. Coyne ${ }^{3}$ \\ Department of Horticulture, University of Nebraska, Lincoln, NE 68583-0724 \\ Additional index words. tissue culture, multiple bud induction, benzyladenine, Phaseolus vulgaris, P. acutifolius
}

\begin{abstract}
A new in vitro protocol was developed for multiple bud induction and plant regeneration from embryonic axis explants of four common bean (Phaseolus vulgaris L.) and two tepary bean ( $P$. acutifolius A. Gray) lines. The explants were prepared from two embryo sizes, 3 to $4 \mathrm{~mm}$ and 5 to $7 \mathrm{~mm}$, corresponding to pods collected after 15 and 25 days from flowering, respectively. The embryonic axis was cultured on Gamborg's $B_{5}$ basal medium with 0 , 5,10 , or $20 \mu \mathrm{M} \mathrm{BA}$ in combinations with 0 , 1, or $2 \mu \mathrm{M}$ NAA. The cultures were maintained at 24 to $25 \mathrm{C}$ under continuous light or incubated in darkness for 2 weeks followed by continuous light before transfer to the secondary $B_{5}$ medium (0 or $2 \mu \mathrm{M}$ BA or $2 \mu \mathrm{M}$ BA plus $4 \mu \mathrm{M} \mathbf{G A}_{3}$ ). Adventitious roots or a single shoot with roots formed on the explants cultured on media without plant growth regulators. Multiple buds were induced on all BA media, but more were produced with 5 or $10 \mu \mathrm{M}$ for most lines. Dark incubation greatly enhanced multiple bud initiation. Shoot buds were not produced on media containing NAA alone or in combinations with BA. On the secondary medium, six to eight shoots per explant for common bean and up to 20 shoots per explant from tepary bean were observed after 3 weeks. Mature, fertile plants were produced from these shoots. Chemical names used: benzyladenine (BA); 1naphthaleneacetic acid (NAA); gibberellic acid $\left(\mathrm{GA}_{3}\right)$.
\end{abstract}

Efficient, repeatable, and rapid in vitro regeneration systems are a prerequisite for using recent advances in biotechnology to improve crop plants. Genetic transformation is one of the interesting areas of biotechnology for plant breeders because characteristics can be added with minimal alteration of the target plant's genome. Therefore, direct shoot morphogenesis from the primary tissues is more desirable than going through an intermediate callus phase (Karp et al., 1982; Kovacs, 1985; Larkin and Scowcroft, 1981; Stiekema et al., 1988).

A protocol for direct shoot organogenesis from cotyledonary node tissues was reported recently by McClean and Grafton (1989) in common bean (P. vulgaris). Also, shoot bud formation at the proximal notches from in vitro cultures of developing cotyledonary explants was described and its potential applications were discussed by Mohamed et al. (1991). However, plant regeneration from induced multiple buds and via direct shoot bud organogenesis from embryonic axis explants has not been reported in Phaseolus spp. If regenerative, the genotype of this explant could be produced in abundance from few seeds, and the explant meristematic tissues could be used directly for foreign gene insertion to produce transgenic plants (McCabe et al., 1988). Shoot bud organogenesis from embryonic explants also could be used to increase the efficiency of in vitro production of $F_{1}$ hybrids in certain interspecific crosses that fail to germinate using the regular embryo rescue procedures (Chen et al., 1990).

The primary objective of this study was to develop a protocol for multiple shoot bud induction and regeneration of bean plants

Received for publication 3 May 1991. Accepted for publication 17 Oct. 1991. Published as Paper no. 9390, Journal Series, Nebraska Agricultural Research Div. Research was conducted under Project 20-036. We gratefully acknowledge the financial support of the Title XII Bean/Cowpea CRSP Program (AID Contract no. DAN-1310-G-SS-6008-00). The cost of publishing this paper was defrayed in part by the payment of page charges. Under postal regulations, this paper therefore must be hereby marked advertisement solely to indicate this fact.

${ }^{1}$ Visiting Scientist from Dept. of Horticulture, Univ. of Assiut, Assiut, Egypt. ${ }^{2}$ Professor and Head.

${ }^{3}$ George Holmes Professor. from tissue cultures of embryonic axis explants. Specific objectives were: 1) to determine the importance of a primary incubation in darkness on shoot bud induction and 2) to investigate the effects of in vitro culture medium and the diversity among different lines of common and tepary beans on bud initiation, proliferation, and rooting.

\section{Materials and Methods}

Plant material and explant preparation. The lines used were four common bean, Great Northern (GN) 'UI 59' and 'Harris', 'PC 50' and Xan 159 (CIAT), and two tepary bean, T\#813L179 and T\#L242-45. The four lines of common bean were selected based on their wide genetic diversity and their value and use in the bean genetic and breeding program in Nebraska. GN 'UI 59' (good seed quality) is of meso-american origin. GN 'Harris' (Coyne et al., 1980) and Xan 159 (McElroy, 1985) possess genes derived from P. acutifolius and are resistant to common bacterial blight [Xanthomonas campestris pv phaseoli (Smith) Dye]. 'PC 50' (F. Saladin, Dominican Republic, unpublished) has nonspecific resistance to rust. The two tepary lines have higher levels of resistance to this pathogen than the common beans (Zaiter et al., 1989).

Seeds of the six lines were planted on 15 May and 20 Aug. 1989. Sixteen plants (two plants in each of eight pots) of each line were grown in the greenhouse under the prevailing natural photoperiods at $40^{\circ} 51^{\prime} \mathrm{N}$ latitude, Lincoln, Neb. The greenhouse was maintained at $26 \mathrm{C}$ day/20C night throughout both experiments. The pots contained 1.8 liters of a mixture of 2 soil : 2 sand : 2 sphagnum peat : 1 vermiculite. Embryo sizes of 3 to $4 \mathrm{~mm}$ and 6 to $7 \mathrm{~mm}$ were obtained from randomly collected pods 15 and 25 days from flowering, respectively, for the experiments conducted at the two planting dates. Separate analyses of variance were conducted for data obtained from the two embryo sizes because they came from plants of different ages. (10 days' difference).

Embryonic axis explants were prepared under aseptic conditions. Pods were collected, then placed in $70 \%$ ethanol and stirred for 1 to 2 min followed by placing the pods in $15 \%$ (v/ v) of a 5.25\% sodium hypochlorite solution with two to three 
drops of Tween-20 (Sigma, St. Louis) per liter and stirred for 15 to $20 \mathrm{~min}$. Pods were then rinsed three times with sterile distilled water. Seed coats were removed and the two cotyledons were separated from the embryos. The plumules and radicles were cut off, and 1 to $2 \mathrm{~mm}$ segments of the embryonic axes (Fig. 1A) were used for in vitro culture.

Media and culture conditions. The basal medium employed for cultures contained Gamborg's $B_{5}$ salts and vitamins (Gamborg et al., 1968) $20 \mathrm{~g}$ sucrose/liter and $8 \mathrm{~g}$ Difco Bacto agar/ liter. Basal medium was used alone or supplemented with 5, 10 , or $20 \mu \mathrm{M}$ BA. Each of the BA concentrations also was tested in combination with 1 or $2 \mu \mathrm{M}$ NAA. The $\mathrm{pH}$ of the media was adjusted to 5.5 before autoclaving. Media were dis-
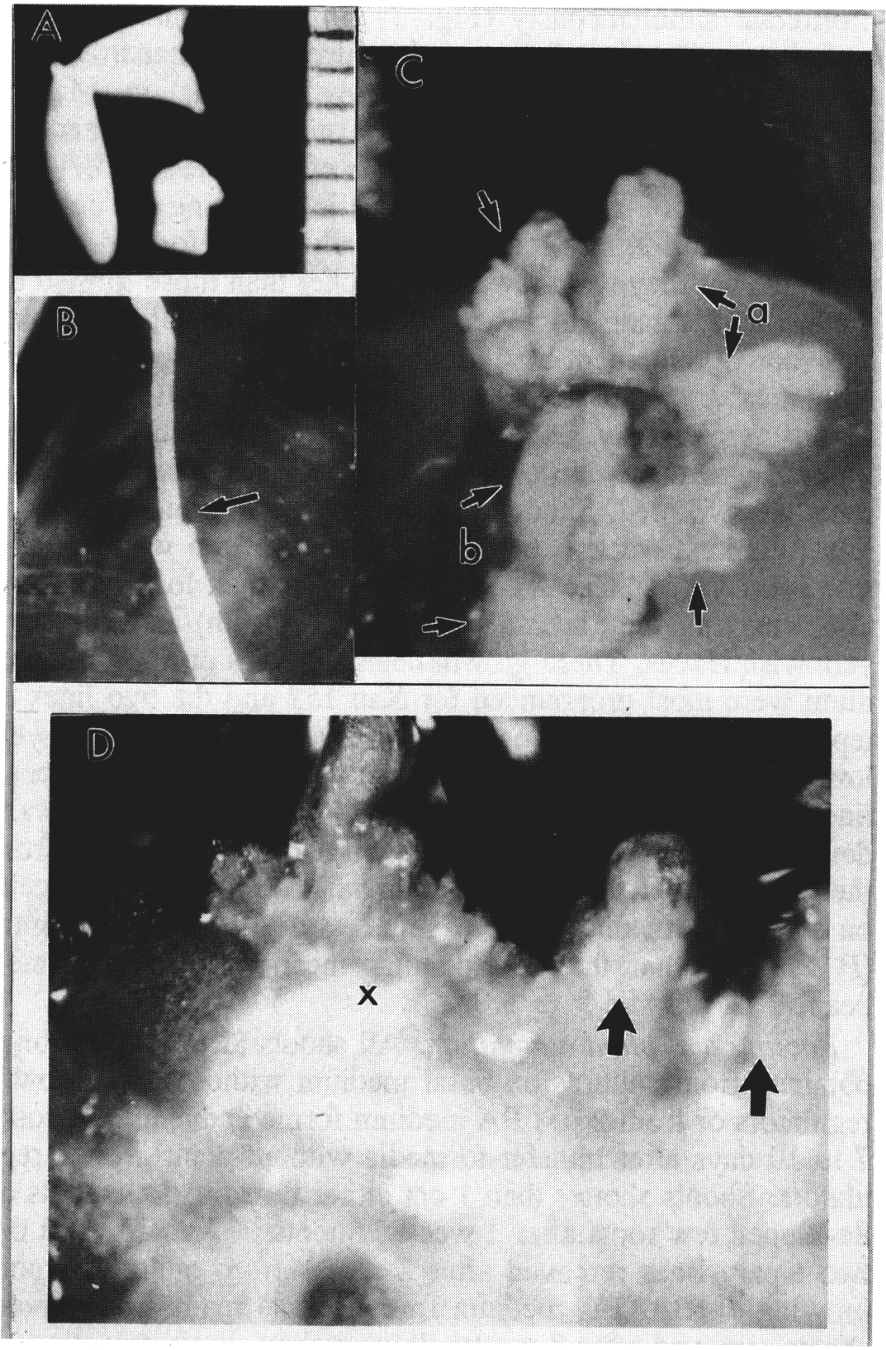

Fig. 1. In vitro cultures of the embryonic axis explant from common and tepary beans. (A) Explant before culture; left: excised embryos; right: prepared explant following radicle and plumule removal. (B) Single shoot formed at the site of the removed plumule (arrow) on basal medium without plant growth regulators. (C) Multiple shoot buds developed on both sides ( $a$ and $b$ ) of the explant on BA medium at 5 or $10 \mu \mathrm{M}$. Note the initiation of adjacent clusters of shoot buds (arrows) on each side. (D) Free hand cross section passing through multiple shoot buds of one side of the explant [as in (C)] that shows a de novo initiation (arrows) of new buds beside and around the axillary multiple bud (x). (B)-(D) are representative photographs showing the developments observed in common for all lines after 3 weeks of the primary culture ( 2 weeks in darkness followed by continuous light for 1 week). pensed into $90 \times 25 \mathrm{~mm}$ glass tubes capped with polypropylene closures and autoclaved at $120 \mathrm{C}$ and $1.2 \mathrm{~kg} \cdot \mathrm{cm}^{-2}$ for $20 \mathrm{~min}$.

Factorial treatment combinations of media and bean lines were arranged in a randomized complete block design for each planting date. Each treatment was represented by 24 explants (6 replicates $\times 4$ tubes each). Cultures were maintained at 24 to $25 \mathrm{C}$ under continuous light $\left(25 \mu \mathrm{mol} \cdot \mathrm{m}^{-2} \cdot \mathrm{s}^{-1}\right)$ from cool-white fluorescent tubes or incubated in darkness for 2 weeks followed by continuous light for 1 week. It was necessary to keep the meristematic tissues of the embryonic axes in direct contact with the medium to develop regular induction of large multiple buds (data not shown). Therefore, all cultures were checked after 1 week to remove the elongated hypocotyls that tended to push the meristematic tissues of the axes above the surface of medium. Percentage of explants developing multiple buds was recorded after 3 weeks on the primary culture.

Since few explants developed shoot buds under continuous light, we used only explants from primary dark-incubated cultures. Explants with multiple buds from the primary culture for each line within each embryonic explant were sampled at random and cultured on three secondary media. These three secondary media were the basal medium without plant growth regulators or basal medium with reduced $\mathrm{BA}$ concentration $(2$ $\mu \mathrm{M})$ alone or plus $\mathrm{GA}_{3}\left(2 \mu \mathrm{M} \mathrm{BA}+4 \mu \mathrm{M} \mathrm{GA}_{3}\right)$. Shoot number per explant $(>0.5 \mathrm{~cm})$ was counted after 3 weeks on each of the secondary media.

Individual shoots $(>1 \mathrm{~cm})$ were harvested regularly from the multiple shoots growing on the secondary medium and transferred to a medium without plant growth regulators for rooting. The resultant plantlets were transplanted after 3 weeks into small pots containing 0.3 to 0.4 liter of soil mixture ( 1 soil : 1 sand : 5 sphagnum peat : 5 vermiculite) and placed under a transparent plastic cover in the laboratory. Half-strength Hoagland's nutrient solution was used to water these plants, as needed (Hoagland and Arnon, 1950). The growing plants were moved after 10 to 15 days to larger pots containing 1.8 liters of the soil mixture used for seed planting, and were placed in a greenhouse. Mature plants were observed for their growth and developmental characteristics.

\section{Results and Discussion}

Shoot bud initiation and development. Friable callus and rhizogenesis were induced on a medium with NAA alone (1 or 2 $\mu \mathrm{M})$, but shoot buds never formed. Also, callus induction occurred under all NAA/BA combinations. Occasionally, shoot buds were initiated on NAA medium plus BA $(5$ or $10 \mu \mathrm{M})$, but these shoot bud initials had an abnormal appearance. They deteriorated and formed callus within 3 to 5 days. However, shoot buds were not produced on media combining NAA with $20 \mu \mathrm{M}$ BA. In spite of callus development on the medium containing BA at $20 \mu \mathrm{M}$, explants with multiple buds were found. Minimum callus was formed on BA medium at 5 or $10 \mu \mathrm{M}$, and it was mostly initiated on the edge of the distal basal region of the embryonic axis where the radicles had been removed.

Embryonic axes cultured on basal medium without plant growth regulators formed roots or a single shoot with adventitious roots. Single plantlets $(2$ to $3 \mathrm{~cm}$ ) on medium without plant growth regulators were ready for acclimatization by the end of the primary culture passage ( 3 weeks). Single shoots from the embryonic axes on medium without plant growth regulators were usually initiated from the residual tip meristem regions at the site of the removed plumules (Fig. 1B).

Lateral regions of the embryonic axis cultured on BA-con- 
taining media became enlarged during 2 weeks of dark incubation before undergoing multiple bud initiation from primary cultures. After a week under continuous light, these cultures developed light green clusters of multiple shoot buds on both sides of the explant (Fig. 1C). In addition to a relatively larger multiple bud cluster on each side of the explant, several smaller and adjacent clusters or single buds were observed to form de novo. A similar phenomenon was described for common bean by McClean and Grafton (1989) and for peas (Pisum sativum L.) by Jackson and Hobbs (1990) in cotyledonary node cultures. Jackson and Hobbs (1990) reported that the axillary meristem suppressed but did not prevent organogenesis of new meristem around and adjacent to the axillary shoots on BA-containing medium (1 mg.liter $\left.{ }^{-1}\right)$. However, wounding during the removal of the axillary meristem was suggested to stimulate the induction of adventitious meristems in cotyledonary node culture of common bean (McClean and Grafton, 1989). The embryonic axis used here was wounded due to plumule and cotyledon separation. Although a histological study was not conducted, both multiple axillary bud proliferation and development of newly induced buds could have occurred (Fig. 1D) from embryonic axis cultures.

Explants on BA medium under continuous light showed early shoot formation and irregular shoot bud multiplication. A lower percentage of explants of most lines developed shoot buds under continuous light than in darkness (Fig. $2 \mathrm{~A}$ and B vs. C and D; $\mathrm{E}$ and $\mathrm{F}$ vs. $\mathrm{G}$ and $\mathrm{H}$ ). Our results agreed with those of Barwale et al. (1986) who observed that an initial dark period enhanced shoot organogenesis from immature embryo callus in soybean [Glycine max (L.) Merr.].

The highest percentage of explants of most lines developed multiple shoot buds on media with 5 or $10 \mu \mathrm{M}$ BA. These results were similar to those for the cotyledonary node cultures in common bean (McClean and Grafton, 1989). Also, some results were in agreement with those of Saam et al. (1987) for shoot multiplication from shoot tip cultures. They obtained multiple shoots (two to three shoots) by using BA at 0.3 to $3 \mathrm{mg} \cdot \mathrm{liter}^{-1}$ (i.e., 1.3 to $13.3 \mu \mathrm{M}$ ) and callus was most pronounced at 6 to $20 \mathrm{mg} \cdot \operatorname{liter}^{-1}$ (26.6 to $\left.88.8 \mu \mathrm{M}\right)$.

Higher competence was expressed for multiple bud formation and the adjacent new bud initiation from explants of Xan 159 and the tepary lines than from the other lines of common bean. Average seed weight of common bean lines was $0.28 \mathrm{~g}$ for $\mathrm{GN}$ 'Harris' and 'UI 59', and $0.42 \mathrm{~g}$ for 'PC 50'. Average seed weight of the two tepary bean lines was 0.17 and $0.15 \mathrm{~g}$. Xan 159 ( $0.25 \mathrm{~g})$ was closer in seed weight to GN 'Harris' and 'UI 59'. It seems that the higher competence of Xan 159 was, therefore, not related to seed weight but more likely was due to its genetic relationship with tepary bean, since it was derived from an interspecific cross between common and tepary beans (McElroy, 1985).

Shootproliferation and elongation. There were no differences in shoot number per explant from similar embryonic explants of all lines on $2 \mu \mathrm{M}$ BA secondary medium in comparison to the control (medium without plant growth regulators). Significant differences $(P<0.05)$ were detected for shoot number per explant only on the $\mathrm{BA} / \mathrm{GA}_{3}$ secondary medium using explants from 3- to 4-mm embryos of T\#81-3L179 over the control; the applicable means from May and August plantings were $21.2 \pm$ 2.1 vs. $17.2 \pm 2.8$ and $24.0 \pm 1.6$ vs. $18.1 \pm 2.6$, respectively. These results on shoot count suggest that the initial induction of multiple shoot buds during the primary cultures is the critical event (Selva et al., 1989). However, unique growth characteristics were observed for shoot proliferation on each of the three secondary media. Roots were formed on the base of the multiple shoot masses, and occasionally on elongated stems of individual shoots on medium without plant growth regulators. Frequently, one and sometimes two shoots grew much taller than the other shoots that proliferated from an individual bud cluster on medium without plant growth regulators, suggesting a possible apical dominance effect. Apical dominance has been found in soybean (Cheng et al., 1980) and winged bean [Psophocarpus tetragonolobus (L.) D.C.], (Blackmon and Reynolds, 1982). On medium containing BA $(2 \mu \mathrm{M})$, shoots had darker green leaves and shorter stems $(1$ to $1.5 \mathrm{~cm})$ than those shoots proliferating on medium without plant growth regulator supplements $(2$ to $2.5 \mathrm{~cm}$ ). Several shoots were observed to proliferate simultaneously (Fig. 3) from each multiple shoot bud, suggesting a requirement of reduced BA concentration in the secondary medium for shoot growth stimulation (Martins and Sondahl, 1984). Our observations on shoot development for media containing BA also suggest the effectiveness of BA as a cytokinin (Skoog and Schmitz, 1972) in removing the possible residual apical dominance. Occasionally, roots formed on BA medium, but they were fewer and thicker than those formed on the medium lacking BA. The results for shoot apical dominance and root development on basal medium without plant growth regulators or with $\mathrm{BA}(2 \mu \mathrm{M})$ were common to all bean lines. In the present study, using $4 \mu \mathrm{M} \mathrm{GA}$ in combination with the $2 \mu \mathrm{M}$ BA medium, uniform shoot growth was observed but no roots were formed. Shoots on $\mathrm{BA} / \mathrm{GA}_{3}$ medium elongated rapidly (within 2 weeks), but the shoots were thin with reduced leaf area. When these shoots remained 1 week longer on BA/ $\mathrm{GA}_{3}$ medium, they became very long $(>4 \mathrm{~cm})$ and thin with yellowish leaves. These growth characteristics on BA/GA 3 medium were most pronounced for Xan 159 and the two lines of tepary bean. A high frequency of shoots with early formed yellow leaves and dead shoots was observed for the common bean lines, GN 'UI 50', 'PC 50', and GN 'Harris'. Tepary beans developed $17 \pm 0.6$ and $9.8 \pm 0.6$ shoots per explant from the two different sets of embryonic axis explants after 3 weeks on secondary medium. These values were significantly higher (P $<0.001)$ than the corresponding mean values for common bean, $7 \pm 0.3$ and $5 \pm 1.0$.

Rooting and plant adaptation. All shoots (1 to $2.5 \mathrm{~cm}$ long) obtained from cultures on basal medium without plant growth regulators or from $2 \mu \mathrm{M}$ BA medium formed adventitious roots 7 to 10 days after transfer to media without plant growth regulators. Shoots shorter than $1 \mathrm{~cm}$ either failed to form roots or developed few roots after 2 weeks. Shoots of Xan 159 and the two tepary lines removed after 2 weeks from multiple shoots growing on $\mathrm{BA} / \mathrm{GA}_{3}$ medium formed roots readily. However, shoots removed after 3 weeks showed slow, limited rooting.

The survival rate of transplants during acclimatization was $100 \%$. Greenhouse-grown plants were uniform and showed no apparent differences in growth habit, leaf shape, flower color, pod shape, or seed color and had no pod set problems.

In conclusion, we have described an in vitro protocol for inducing multiple shoots from embryonic axes and regeneration of fertile plants in common and tepary beans. This method offers a new source of explants that could be used for producing multiple copies from unique genotypes of beans via axillary multiple-shoot proliferation and direct shoot bud induction. This system may further be useful to 1) produce transgenic beans by introducing foreign DNA into meristem tissues of the embryos using the electric discharge acceleration method of DNA-coated 

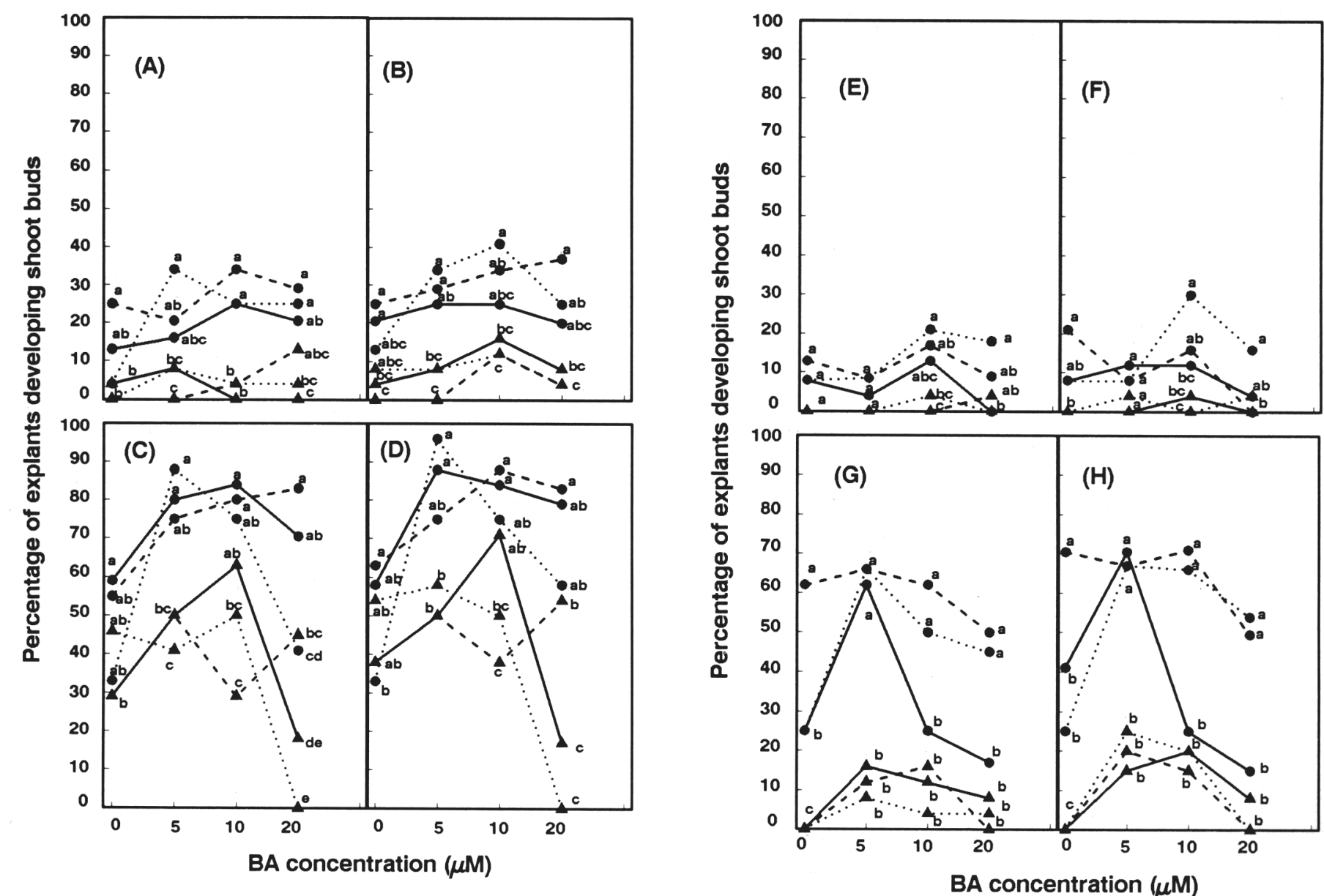

Fig. 2. Percentage of embryonic axis explants developing shoot buds in vitro after 3 weeks in four common bean (CB) and two tepary bean (T) lines using 3- to 4-mm embryos from pods collected 15 days after flowering when maintained under continuous light (A and B) or incubated 2 weeks in darkness (C and D) before transfer to light (from separate May and August plantings, respectively); E-H using 6- to 7-mm embryos from pods collected 25 days after flowering for continuous light $(\mathbf{E}$ and $\mathbf{F})$ and initially dark-incubated $(\mathbf{G}$ and $\mathbf{H})$ cultures

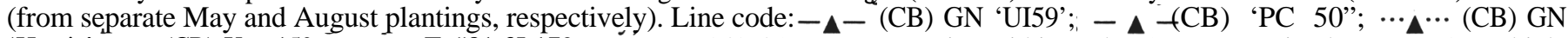
'Harris';,- ((CB) Xan 159; - - - T \#81-3L179; ..•.. T\#L242-45. Mean separation within each BA concentration by Duncan's multiple range test, $\mathrm{P} \leq 0.05$.

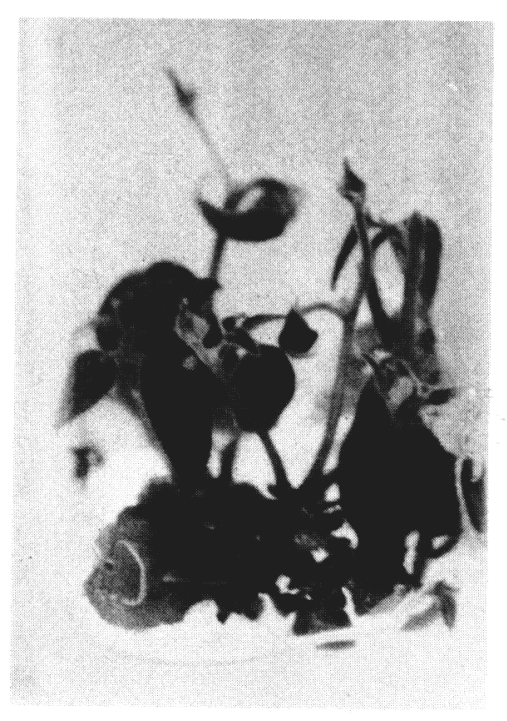

Fig. 3. Shoot proliferation and simultaneous elongation of many shoots on secondary medium with reduced BA level $(2 \mu \mathrm{M})$. gold particles as successfully employed in soybean (McCabe et al., 1988) or via Agrobacterium delivery procedures using suitable disarmed strains and 2) increase the number of $F_{1}$ plants derived from embryo rescue of wide-crosses in Phaseolus.

\section{Literature Cited}

Barwale, U.B., H.R. Kerns, and J.M. Widholm. 1986. Plant regeneration from callus cultures of several soybean genotypes via embryogenesis and organogenesis. Planta 167:473-481.

Blackmon, W.J. and B.D. Reynolds. 1982. In vitro shoot regeneration of Hibiscus acetosella, muskmelon, watermelon, and winged bean. HortScience 17:588-589.

Chen, H.K., M.C. Mok, and D.W.S. Mok. 1990. Somatic embryogenesis and shoot organogenesis from interspecific hybrid embryos of Vigna glabrescens and V. radiata. Plant Cell Rpts. 9:77-79.

Cheng, T., H. Saka, and T.H. Voqui-Dinh. 1980. Plant regeneration from soybean cotyledonary node segments in culture. Plant Sci. Lett. 19:91-99.

Coyne, D.P., D.S. Nuland, M.L. Schuster, and F.N. Anderson. 1980. 'Great Northern Harris' dry bean. HortScience 15:531.

Gamborg, O.L., R.A. Miller, and K. Ojima. 1968. Nutrient requirements of suspension cultures of soybean root cells. Expt. Cell Res. 50:151-158. 
Hoagland, D.R. and D.I. Arnon. 1950. The water-culture method for growing plants without soil. California Agr. Expt. Sta. Bul. no. 347.

Jackson, J.A. and S.L. Hobbs. 1990. Rapid multiple shoot production from cotyledonary node explants of pea (Pisum sativum L.). In Vitro Cellular Dev. Biol. 26:835-838.

Karp, A., R.S. Nelson, E. Thomas, and S.W. Bright. 1982. Chromosome variation in protoplast-derived potato plants. Theoretical Applied Genet. 63:265-272.

Kovacs, E.I. 1985. Regulation of karyotype stability in tobacco tissue cultures of normal and tumorous genotypes. Theoretical Applied Genet. 70:548-554.

Larkin, P.J. and W.R. Scowcroft. 1981. Somaclonal variation-a novel source of variability from cell cultures for plant improvement. Theoretical Applied Genet. 60:197-214.

Martins, I.S. and M.R. Sondahl. 1984. Axillary bud development from nodal cultures of bean seedlings (Phaseolus vulgaris L.) Turrialba 34:157-161.

McCabe D.E., W.F. Swain, B.J. Martinell, and P. Christou. 1988. Stable transformation of soybean (Glycine max) by particle acceleration. Bio/Technology 6:923-926.

McClean, P. and K.F. Grafton. 1989. Regeneration of dry bean (Phaseolus vulgaris L.) via organogenesis. Plant Sci. 60:117122.
McElroy, J.B. 1985. Breeding dry beans (Phaseolus vulgaris L.) for common bacterial blight resistance derived from Phaseolus acutifolius A. Gray. PhD Diss., Cornell Univ., Ithaca, N.Y.

Mohamed, M.F., P.E. Read, and D.P. Coyne. 1991. In vitro response of bean (Phaseolus vulgaris L.) cotyledonary explants to benzyladenine in the medium. Plant Growth Regulat. Soc. Amer. Quart. 19:19-26.

Saam, M.M., G.L. Hosfield, and J.W. Saunders. 1987. In vitro propagation of dry bean from seedling shoot tips. J. Amer. Soc. Hort. Sci. 112:852-855.

Selva, E., B. Stovffs, and M. Briquet. 1989. In vitro propagation of Vicia faba L. by micro-cutting and multiple shoot induction. Plant Cell Tissue Organ Cult. 18:167-179.

Skoog, F. and R.Y. Schmitz. 1972. Cytokinins, p. 181-212. In: F.C. Steward (ed.). Plant physiology: A treatise. vol. VI B. Academic, New York/London.

Stiekema, W.J., F. Heidekamp, J.D. Louwerse, H.A. Verhoeven, and P. Dijkhuis. 1988. Introduction of foreign gene into potato cultivars Bintje and Desiree using an Agrobacterium tumefaciens binary vector. Plant Cell Rpts. 7:47-50.

Zaiter, H.Z., D.P. Coyne, A.K. Vidaver, and J.R. Steadman. 1989. Differential reaction of tepary bean lines to Xanthomonas campestris pv. phaseoli. HortScience 24:134-137. 